\title{
PENGARUH LINGKUNGAN KERJA TERHADAP MOTIVASI KERJA KARYAWAN PADA PT. PUPUK SRIWIDJAJA PALEMBANG, PUSRI PEMASARAN DAERAH (PPD) JAWA TENGAH
}

\author{
Heni Ingsiyah, Putut Haribowo ${ }^{2}$, Isnaini Nurkhayati \\ Administrasi Bisnis, Politeknik Negeri Semarang, Semarang, Indonesia \\ email: ${ }^{2}$ putut haribowo@polines.ac.id
}

\begin{abstract}
The purposes of this research were to find out (1) The influence of physical work environment on employees' work motivation at PT. Pusri Palembang, PPD Jateng, (2) The influence of nonphysical work environment on employees' work motivation at PT. Pusri Palembang, PPD Jateng, and (3) work environment on employees work motivation at PT. Pusri Palembang, PPD Jateng. This study was a survey method with questionnaires, and literature study. The sample in this study were 35 employees' of the PT. Pusri Palembang, PPD Jateng. The data analysis technique used was multiple regression. From the analysis of multiple regression in this research, it could be found that the physical work environment and non-physical work environment had positive impact on the employees' work motivation. The most dominant variable that positively influenced the employees' work motivation was the non physical work environment. While from the result of determination coefficient (Adjusted $R$ Square) showed that 0,46 or $46 \%$ of the independent variable were physical work environment and non-physical work environment. It meant that $46 \%$ of the employees' work motivation was explained by work environment. While $54 \%$ was explained by other factors not examined in this research.
\end{abstract}

Keywords: work environment and work motivation

PENGARUH LINGKUNGAN KERJA TERHADAP MOTIVASI KERJA KARYAWAN

PADA PT. PUPUK SRIWIDJAJA PALEMBANG, PUSRI PEMASARAN DAERAH (PPD) JAWA TENGAH

\begin{abstract}
Abstrak
Tujuan penelitian ini adalah untuk mengetahui (1) Pengaruh lingkungan kerja fisik terhadap motivasi kerja karyawan pada PT. Pusri Palembang, PPD Jateng, (2) Pengaruh lingkungan kerja non fisik terhadap motivasi kerja karyawan di PT. Pusri Palembang, PPD Jateng, dan (3) lingkungan kerja pada motivasi kerja karyawan di PT. Pusri Palembang, PPD Jateng. Penelitian ini adalah metode survei dengan kuesioner, dan studi pustaka. Sampel dalam penelitian ini adalah 35 karyawan PT. Pusri Palembang, PPD Jateng. Teknik analisis data yang digunakan adalah regresi berganda. Dari analisis regresi berganda dalam penelitian ini, dapat ditemukan bahwa lingkungan kerja fisik dan lingkungan kerja non-fisik memiliki dampak positif terhadap motivasi kerja karyawan. Variabel yang paling dominan yang secara positif mempengaruhi motivasi kerja karyawan adalah lingkungan kerja non fisik. Sedangkan dari hasil koefisien determinasi (Adjusted R Square) menunjukkan bahwa 0,46 atau 46\% variabel independen adalah lingkungan kerja fisik dan lingkungan kerja non fisik. Itu berarti bahwa $46 \%$ motivasi kerja karyawan dijelaskan oleh lingkungan kerja. Sedangkan 54\% dijelaskan oleh faktor lain yang tidak diteliti dalam penelitian ini.
\end{abstract}

Kata kunci: lingkungan kerja dan motivasi kerja 


\section{PENDAHULUAN}

Pada dasarnya setiap perusahaan memiliki tujuan yang ingin dicapai, oleh sebab itu perusahaan diharapkan memiliki sumber daya manusia yang berkualitas. Sumber daya manusia merupakan komponen yang paling penting dalam suatu organisasi, karena memiliki peran sebagai mengemudi dan mengendalikan kegiatan organisasi (Riyanto et.al, 2017:342).

Guna tercapainya tujuan perusahaan, motivasi kerja sangat penting bagi karyawan karena motivasi dapat memberikan dorongan dan semangat sehingga hasil kerja karyawan lebih optimal. Hal ini di dukung pendapat dari Manullang (2015:166) yang menyatakan bahwa motivasi kerja tidak lain dari sesuatu yang menimbulkan dorongan atau semangat kerja.

Motivasi dipengaruhi oleh beberapa faktor, Sutrisno (2009:116-120) membedakan faktor motivasi menjadi dua yaitu faktor intern dan faktor ekstern. Salah satu faktor ekstern yang perlu di perhatikan dalam motivasi kerja adalah lingkungan kerja, hal ini didukung dengan Hasil penelitian Noor (2014) yang menunjukan hasil bahwa lingkungan kerja berpengaruh terhadap motivasi kerja Satuan Kerja Unit Pelaksana Penimbangan (Jembatan Timbang) Dinas Perhubungan dan LLAJ Jawa Timur dengan arah hubungan positif.

Lingkungan kerja fisik dan lingkungan kerja non fisik merupakan salah satu faktor motivasi ekstern yang berpengaruh positif terhadap motivasi kerja karyawan, hal ini didukung pula oleh penelitian yang dilakukan oleh Simamora dll (2016) menunjukan hasil lingkungan kerja fisik dan lingkungan kerja non fisik secara signifikan berpengaruh terhadap motivasi kerja karyawan Hotel Atria dan Konferensi Malang.

Pusri Pemasaran Daerah (PPD) Jawa tengah (Jateng) merupakan kantor perwakilan PT. Pupuk Sriwidjaja Palembang yang berfungsi sebagai pelaksana teknis dalam penjualan produk dan mewakili kepentingan perusahaan di daerah Jawa Tengah. Jumlah absensi karyawan PT. Pusri, PPD Jateng pada Januari 2017 - April 2018 menunjukan masih terdapat karyawan yang absen atau tidak hadir, presentase karyawan absen tertinggi adalah 9\% yaitu pada bulan Maret dan April 2018.

Perusahaan harus lebih memperhatikan karyawan karena masih adanya karyawan yang tidak masuk kerja tanpa alasan, karyawan diharapkan mempunyai motivasi kerja tinggi agar mendapatkan hasil kerja yang optimal dan tujuan perusahaan dapat tercapai.

Berdasarkan uraian latar belakang tersebut, maka peneliti tertarik untuk melakukan penelitian dengan judul "Pengaruh Lingkungan Kerja Terhadap Motivasi Kerja Karyawan Pada PT. Pupuk Sriwidjaja Palembang, Pusri Pemasaran Daerah (PPD) Jawa Tengah"

Perumusan dan Tujuan

Berdasarkan pada uraian latar belakang, penelitian ini dimaksudkan untuk mengetahui bagaimana meningkatkan motivasi kerja karyawan melalui lingkungan kerja pada PT. Pupuk Sriwidjaja Palembang, PPD Jateng. Berdasarkan rumusan masalah tersebut, maka dikembangkan pertanyaan sebagai berikut:

a. Bagaimana pengaruh lingkungan kerja fisik terhadap motivasi kerja karyawan PT. Pupuk Sriwidjaja Palembang, PPD Jateng?

b. Bagaimana pengaruh lingkungan kerja non fisik terhadap motivasi kerja karyawan PT. Pupuk Sriwidjaja Palembang, PPD Jateng?

c. Bagaimana pengaruh lingkungan kerja terhadap motivasi kerja PT. Pupuk Sriwidjaja Palembang, PPD Jateng?

Penelitian ini dilakukan dengan tujuan sebagai berikut:

a. Menganalisis pengaruh lingkungan kerja fisik terhadap motivasi kerja karyawan PT. Pupuk Sriwidjaja PPD Jateng 
b. Menganalisis pengaruh lingkungan kerja non fisik terhadap motivasi kerja karyawan PT. Pupuk Sriwidjaja PPD Jateng

c. Menganalisis pengaruh lingkungan kerja terhadap motivasi kerja karyawan PT. Pupuk Sriwidjaja PPD Jateng

Tinjauan Pustaka

Motivasi kerja

Motivasi menurut Sutrisno (2010:109) adalah "Suatu faktor yang mendorong seseorang untuk melakukan suatu aktivitas tertentu, oleh karena itu motivasi sering kali diartikan pula sebagai faktor pendorong perilaku seseorang". Sutrisno (2009:116-120), mengemukakan motivasi sebagai proses psikologis dalam diri seseorang akan dipengaruhi oleh beberapa faktor. Faktor-faktor tersebut dapat dibedakan atas faktor intern dan ekstern yaitu sebagai berikut:

a. Faktor Intern

1. Keinginan untuk dapat hidup

2. Keinginan untuk dapat memiliki

3. Keinginan untuk memperoleh penghargaan

4. Keinginan untuk memperoleh pengakuan

5. Keinginan untuk berkuasa

b. Faktor Ekstern

1. Kondisi lingkungan kerja

2. Kompensasi yang memadai

3. Supervisi yang baik

4. Adanya jaminan pekerjaan

5. Status dan tanggung jawab

6. Peraturan yang fleksibel

Pada penelitian ini indikator variabel motivasi kerja yang digunakan mengadopsi dari beberapa indikator yang digunakan dalam penelitian Asmirin Noor (2014), yaitu:
a. Achievement (Prestasi)
b. Recognition (Pengakuan)
c. Responsibility (Tanggung jawab)
d. Advancement (Peluang untuk maju)
e. Kondisi Kerja

Lingkungan Kerja
Menurut Sedarmayanti dalam Lumbatoruan (2013:734) mengemukakan bahwa secara garis besar, jenis lingkungan kerja terbagi menjadi 2 (dua) yaitu:

a. Lingkungan Kerja Fisik

Lingkungan kerja fisik adalah semua keadaan berbentuk fisik yang terdapat di sekitar tempat kerja yang dapat mempengaruhi pegawai baik secara langsung maupun tidak langsung. Lingkungan kerja fisik dapat dibagi menjadi dua kategori yaitu:

1. Lingkungan kerja yang langsung berhubungan dengan pegawai seperti pusat kerja, kursi, meja, dan sebagainya.

2. Lingkungan perantara atau lingkungan umum

b. Lingkungan Kerja Non Fisik

Lingkungan kerja non fisik adalah semua keadaan yang terjadi yang berkaitan dengan hubungan kerja, baik hubungan dengan atasan maupun hubungan sesama rekan kerja, ataupun hubungan dengan bawahan

Pada penelitian ini indikator variabel lingkungan kerja fisik dan non fisik yang digunakan, mengadopsi beberapa indikator lingkungan kerja yang dikemukakan Sedarmayanti dalam Aslinda (2017:20) yaitu:

a. Indikator Lingkungan Fisik Penerangan, suhu udara, privasi ruang kerja, dan suara bising.

b. Indikator Lingkungan Non Fisik Hubungan kerja karyawan dengan sesama rekan kerja dan hubungan kerja antara atasan dengan bawahan

\section{METODE}

Populasi pada penelitian ini adalah karyawan operasional di kantor PT. Pupuk Sriwidjaja, Palembang, PPD Jateng. Teknik sampling yang digunakan pada penelitian ini adalah sampling jenuh, pada teknik pengambilan sampel ini semua anggota populasi dijadikan sampel yaitu 35 karyawan. Menurut Sugiyono (2014: 122) sampling jenuh adalah 
teknik penentuan sampel bila semua anggota populasi digunakan sebagai sampel.

Skala yang digunakan dalam penelitian ini adalah agree-disagree scale. Skala ini merupakan salah satu bentuk lain dari bipolar adjective dengan mengembangkan pernyataan yang menghasilkan jawaban setuju tidak setuju dalam berbagai rentang nilai (Ferdinand, 2014:206).

Metode analisis data yang digunakan adalah:

1. Analisis Deskriptif

Menurut Ferdinand (2006:289) analisis deskriptif digunakan untuk memberikan gambaran deskriptif empiris atas data yang dikumpulkan dalam penelitian.

2. Uji Validitas dan Reliabilitas

Instrumen yang digunakan dalam penelitian ini berupa kuesioner, untuk itu terlebih dahulu instrumen diuji apakah instrumen yang digunakan dalam penelitian ini layak atau tidak. Uji instrumen yang dimaksud adalah uji validitas dan reliabilitas.

3. Uji Asumsi Klasik

Uji asumsi klasik yang digunakan dalam penelitian ini antara lain uji multikolinieritas, uji heteroskesdastisitas, dan uji normalitas.

4. Analisis Regresi Linier Berganda

Analis regresi linier berganda dilakukan untuk mengidentifikasi variabel lingkungan kerja fisik dan lingkungan kerja non fisik yang mempengaruhi motivasi kerja karyawan.

5. Uji Hipotesis

a. Koefisien Determinasi $\left(\mathrm{R}^{2}\right)$

Koefisien determinasi dapat digunakan sebagai petunjuk untuk mengetahui sejauh mana variabel independen dapat menjelaskan variasi variabel dependen (Algifari, 2015:200)

b. Uji t

Uji statistik pada $\mathrm{t}$ pada dasarnya menunjukkan seberapa jauh pengaruh satu variabel penjelas/independen secara individual dalam menerangkan variasi variabel dependen (Ghozali, 2016:97)

c. Uji F

Uji $F$ digunakan untuk mengetahui variabel independen secara bersamasama atau simultan mempengaruhi variabel dependen (Ghozali, 2016:97)

\section{HASIL DAN PEMBAHASAN}

Analisis Deskriptif

Hasil analisis deskriptif dalam penelitian ini adalah sebagai berikut:

1. Variabel Lingkungan Kerja Fisik

Jawaban responden mengenai lingkungan kerja fisik rata - rata sedang yaitu sebesar $69,0 \%$.

2. Variabel Lingkungan Kerja Non Fisik

Jawaban responden mengenai lingkungan kerja fisik rata - rata pada kategori tinggi yaitu sebesar 79,0 \%.

3. Motivasi Kerja Karyawan

Jawaban responden mengenai motivasi kerja rata - rata pada kategori tinggi yaitu sebesar 79,0\%.

Uji Validitas

Suatu kuesioner dikatakan valid jika pertanyaan pada kuesioner mampu mengungkapkan sesuatu yang akan diukur oleh kuesioner tersebut (Ghozali, 2011:52). Adapun metode yang digunakan untuk menguji validitas pada penelitian ini adalah dengan menggunakan software SPSS 22. Hasil uji validitas variabel penelitian didapat bahwa semua butir pertanyaan/pernyataan adalah valid.

Uji Reliabilitas

Suatu kuesioner dikatakan reliabel atau handal jika jawaban seseorang terhadap pernyataan adalah konsisten atau stabil dari waktu ke waktu. Hasil uji tingkat reliabilitas variabel dapat dikatakan bahwa semua variabel reliable. 
Uji Asumsi Klasik

Uji Multikolinieritas

Pengujian multikolinearitas dilakukan dengan melihat nilai VIF (variance-inflating factor), dasar pengambilan keputusan jika VIF $\leq 10$ maka tidak ada gejala multikolinearitas diantara variabel bebas. Tabel 1 merupakan hasil perhitungan menggunakan program SPSS 22.

Tabel 1 Hasil Uji Mulitikolinearitas

\begin{tabular}{|c|c|c|}
\hline \multicolumn{3}{|c|}{ Coefficients $^{\mathrm{a}}$} \\
\hline \multirow[t]{3}{*}{ Model } & $\begin{array}{r}\text { Collin } \\
\text { Stati }\end{array}$ & $\begin{array}{l}\text { earity } \\
\text { tics }\end{array}$ \\
\hline & Toleran & \\
\hline & ce & VIF \\
\hline \multicolumn{3}{|l|}{1 (Constant) } \\
\hline $\begin{array}{l}\text { Lingkungan } \\
\text { fisik }\end{array}$ & ,821 & 1,218 \\
\hline $\begin{array}{l}\text { Lingkungan } \\
\text { Non_Fisik }\end{array}$ & 821 & 1,218 \\
\hline
\end{tabular}

a. Dependent Variable: Motivasi

Sumber: Data primer yang diolah, 2018

Berdasarkan tabel 1 menunjukan bahwa nilai VIF 1,218 artinya nilai VIF dari tabel tersebut lebih kecil dari pada $10(1,218 \leq 10)$. Dengan demikian, dapat disimpulkan bahwa tidak terjadi gerjala multikolinearitas diantara variabel bebas.

Uji Normalitas
Pengujian normalitas dilakukan dengan menggungakan uji statistik KolmogorovSminov Test. Residual berdistribusi normal jika memiliki nilai signigikan $>0.05$, untuk residual regresi menggunakan software SPSS 22. Output yang dihasilkan disajikan pada tabel 2. Berdasarkan tabel 2 diperoleh nilai sig $0,200 \geq 0,05$, maka data tersebut berdistribusi normal.

Tabel 2 Hasil Uji Normalitas

One-Sample Kolmogorov-Smirnov Test

Unstandardize

d Residual

$\mathrm{N} \quad 35$

Normal Mean ,0000000

Parameters $^{\mathrm{a}, \mathrm{b}}$ Std.

Deviatio 7,05382203

$n$

Most ExtremeAbsolute, 119

Differences Positive ,099

Negative -, 119

Test Statistic $\quad, 119$

Asymp. Sig. (2-tailed) $\quad 200^{\mathrm{c}, \mathrm{d}}$

a. Test distribution is Normal.

Sumber: Data primer yang diolah, 2018 
Uji Heteroskesdastisitas

Uji Heteroskesdastisitas bertujuan menguji apakah dalam regresi terjadi ketidaksamaan variance dari residual suatu pengamatan ke pengamatan yang lain. Hasil dari uji heteroskesdastisitas menggunakan scatterplot dapat dilihat pada gambar 1 .

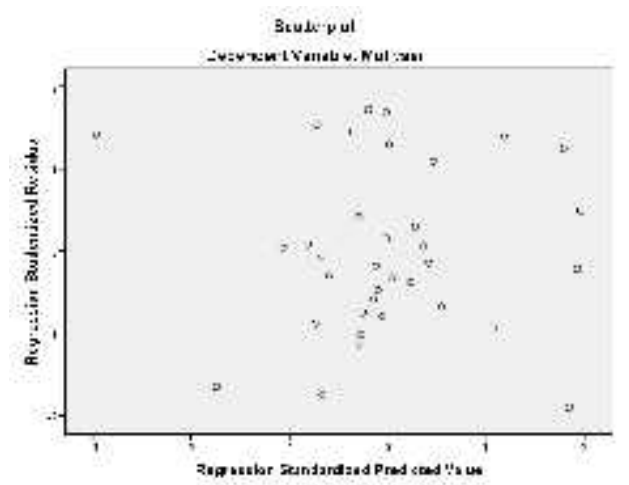

Sumber: Data primer yang diolah, 2018

Gambar 1 Uji Heteroskedastisitas

Berdasarkan gambar 1 menunjukan titik titik menyebar secara acak, baik dibagian atas angka nol atau dibagian angka nol dari sumbu Y. Dengan demikian, dapat disimpulkan bahwa tidak terjadi heteroskesdastisitas dalam model regresi ini.

Analisis Regresi Linier Berganda
Analisis ini digunakan untuk mengetahui variabel - variabel bebas (independen) yaitu lingkungan kerja fisik $\left(\mathrm{X}_{1}\right)$ dan lingkungan kerja non fisik $\left(\mathrm{X}_{2}\right)$, terhadap variabel terikat (dependen) yaitu motivasi kerja karyawan (Y). Berdasarkan hasil pengujian regresi berganda dengan program SPSS 22, diperoleh hasil sebagaimana Tabel 3.

Tabel 3 Hasil Analisis Regresi

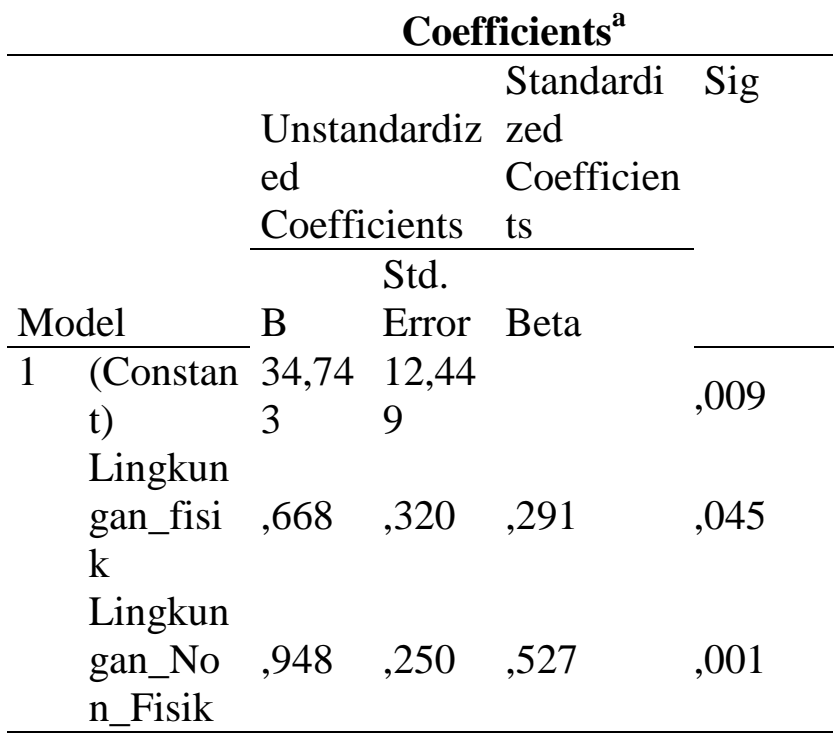

a. Dependent Variable: Motivasi

Sumber: Data primer yang diolah, 2018 
Berdasarkan tabel 3 dapat diketahui bahwa seluruh variabel bebas yaitu lingkungan kerja fisik dan lingkungan kerja non fisik memiliki signifikansi $<0.05$, hal ini berarti variabel bebas berpengaruh terhadap motivasi kerja karyawan. Adapun model regresi linier berganda yang terbentuk adalah sebagai berikut:

$$
\begin{aligned}
& Y=34,743+0,668 X_{1}+0,948 X_{2} \\
& \mathrm{Y}=\text { Motivasi Kerja Karyawan } \\
& \mathrm{X}_{1} \quad=\text { Lingkungan Kerja Fisik } \\
& \mathrm{X}_{2}=\text { Lingkungan Kerja Non Fisik }
\end{aligned}
$$

Keterangan:

a. Konstanta $(\alpha)=34,743$

Artinya jika variabel lingkungan kerja $\left(\mathrm{X}_{1}\right)$ dan lingkungan kerja non fisik $\left(\mathrm{X}_{2}\right)$ nilainya adalah 0 , maka variabel motivasi kerja karyawan (Y) nilainya positif sebesar 34,743

b. Koefisien $X_{1}=0,668$

Nilai koefisien dari variabel lingkungan kerja fisik adalah 0,668 dengan tingkat signifikansi 0,045. Hal ini berarti setiap peningkatan variabel lingkungan kerja fisik akan meningkatkan motivasi kerja karyawan PT. Pusri Palembang, PPD Jateng.

c. Koefisien $X_{2}=0,948$

Nilai koefisien dari variabel lingkungan kerja non fisik adalah 0,948 dengan tingkat signifikansi 0,001 . Hal ini berarti setiap peningkatan variabel lingkungan kerja non fisik akan meningkatkan motivasi kerja karyawan PT. Pusri Palembang, PPD Jateng.

d. Persamaan regresi tersebut, dapat disimpulkan bahwa variabel yang paling dominan berpengaruh terhadap variabel motivasi kerja yaitu lingkungan kerja non fisik dengan nilai koefisien sebesar 0,948.

\section{Koefisien Determinasi}

Pada penelitian ini dalam mengevaluasi model regresi adalah menggunakan Adjusted $\mathrm{R}^{2}$, menurut Ghozali (2016:95) tidak seperti $\mathrm{R}^{2}$, nilai Adjusted $\mathrm{R}^{2}$ dapat naik atau turun apabila satu variabel independen ditambahkan kedalam model.

\begin{tabular}{|c|c|c|c|c|}
\hline \multicolumn{5}{|c|}{ Model Summary } \\
\hline Model & $\mathrm{R}$ & $\begin{array}{l}\mathrm{R} \\
\text { Square }\end{array}$ & $\begin{array}{l}\text { Adjusted } \\
\text { R Square }\end{array}$ & $\begin{array}{l}\text { Std. Error of the } \\
\text { Estimate }\end{array}$ \\
\hline 1 &, $702^{\mathrm{a}}$ &, 492 &, 460 & 7,271 \\
\hline
\end{tabular}

Untuk mengetahui nilai koefisien determinasi pada penelitian ini dapat dilihat pada tabel 4 .

Tabel 4 Hasil Koefisien Determinasi

Sumber: Data primer yang diolah, 2018

UJI t (Uji Parsial)

Pada tabel 4 menunjukan bahwa besarnya Adjusted $R$ Square adalah 0,460 atau $46 \%$ artinya hal ini menunjukan bahwa $46 \%$ motivasi kerja karyawan dipengaruhi variabel independen lingkungan kerja fisik dan lingkungan kerja non fisik, sedangkan sisanya dipengaruhi oleh variabel - variabel lain yang tidak diteliti dalam penelitian ini.
Menurut Ghozali (2016:171) Uji parsial digunakan untuk mengetahui pengaruh masing - masing variabel independen terhadap variabel dependen. Uji t dilakukan dengan cara membandingkan nilai $t_{\text {hitung }}$ dengan nilai $t_{\text {tabel }}$ dengan menggunakan taraf signigikansi 0,05 atau 5\%. Hasil uji t dapat dilihat pada tabel 5 . 
Ingsiyah, dkk/AdBis 20 (1): 83 - 92

Tabel 5 Hasil Uji t

\begin{tabular}{llll}
\hline Variabel & $\mathrm{T}_{\text {hitung }}$ & $\mathrm{T}_{\text {tabel }}$ & Sign \\
\hline Lingkungan Kerja Fisik $\left(\mathrm{X}_{1}\right)$ & 2.090 & 2.037 & .045 \\
Lingkungan Non Fisik $\left(\mathrm{X}_{2}\right)$ & 3.793 & 2.037 & .001 \\
Motivasi Kerja (Y) & 2.791 & 2.037 & .009
\end{tabular}

Sumber: Data primer yang diolah, 2018

Berdasarkan tabel 5 dapat diketahui bahwa nilai dari semua variabel menunjukan $t_{\text {hitung }}$ lebih besar dari $\mathrm{t}$ tabel, maka dapat disimpulkan bahwa pada penelitian ini semua variabel independen secara parsial berpengaruh terhadap variabel dependen.

UJI F (Uji Simultan)
Uji $\mathrm{F}$ digunakan untuk mengetahui variabel independen secara bersama-sama atau simultan mempengaruhi variabel dependen (Ghozali, 2016:171). Uji F dilakukan dengan membandingkan $\mathrm{F}$ hitung dengan $\mathrm{F}$ tabel dengan taraf signifikansi sebesar $5 \%(\alpha=0,05)$. Nilai $\mathrm{f}$ tabel pada tingkat signifikansi $5 \%$ adalah 3,29. Hasil uji simultan dalam penelitian ini dapat dilihat pada tabel 6:

Tabel 6 Hasil Uji F

\begin{tabular}{|c|c|c|c|c|c|}
\hline \multicolumn{6}{|l|}{ ANOVA $^{a}$} \\
\hline Model & $\begin{array}{l}\text { Sum } \\
\text { Squares }\end{array}$ & Df & $\begin{array}{l}\text { Mean } \\
\text { Square }\end{array}$ & $\mathrm{F}$ & Sig. \\
\hline 1 Regression & 1639,825 & 2 & 819,913 & 15,509 &, $000^{\mathrm{b}}$ \\
\hline Residual & 1691,718 & 32 & 52,866 & & \\
\hline Total & 3331,543 & 34 & & & \\
\hline
\end{tabular}

Sumber: Data primer yang diolah, 2018

Berdasarkan pada tabel 6 dapat diketahui bahwa:

$\mathrm{H}_{0} \quad$ : Tidak ada pengaruh yang antara Lingkungan kerja fisik dan non fisik Terhadap Motivasi Kerja karyawan pada PT. Pupuk Sriwidjaja Palembang, PPD Jateng.

$\mathrm{H}_{\mathrm{a}} \quad$ : Ada pengaruh yang antara Lingkungan Kerja Fisik dan Non Fisik Terhadap Motivasi Kerja karyawan pada PT. Pupuk Sriwidjaja Palembang, PPD Jateng.

Nilai $F$ tabel dengan df $1=2$ dan $\mathrm{df} 2=32$ adalah 3,29. Dari tabel 18 dapat diketahui jika $F_{\text {hitung }}$ $>\mathrm{F}_{\text {tabel }}(15,509>3,29)$ dan nilai signifikansi $0,000<0,05$, maka dari itu dapat disimpulkan bahwa $\mathrm{H}_{0}$ ditolak dan $\mathrm{H}_{\mathrm{a}}$ diterima.

\section{SIMPULAN DAN SARAN}

Berdasarkan hasil analisis dalam penelitian Skripsi ini, dapat disimpulkan mengenai pengaruh lingkungan kerja fisik dan lingkungan kerja non fisik terhadap motivasi kerja karyawan pada PT. Pupuk Sriwidjaja Palembang, PPD Jateng adalah sebagai berikut:

a. Lingkungan kerja fisik berpengaruh terhadap motivasi kerja karyawan dengan nilai koefisien regresi 0,668 dan signifikan 0,045 .

b. Lingkungan kerja non fisik berpengaruh terhadap motivasi kerja karyawan dengan nilai koefisien 0,948 dan signifikan 0,001 . 
c. Lingkungan kerja fisik dan lingkungan kerja non fisik secara simultan berpengaruh terhadap motivasi kerja karyawan dengan persamaan $\mathrm{Y}=34,743$ $+0,668 \mathrm{X}_{1}+0,948 \mathrm{X}_{2}$.

d. Variabel yang memiliki pengaruh paling dominan terhadap motivasi kerja karyawan adalah lingkungan kerja non fisik dengan nilai beta sebesar 0,948, sedangkan variabel lingkungan kerja fisik sebesar 0,668. Hal ini berarti bahwa variabel lingkungan kerja non fisik lebih berpengaruh meningkatkan motivasi kerja karyawan dibanding dengan variabel lingkungan kerja fisik.

Saran

Berdasarkan hasil analisis maka saran yang dapat diberikan sebaiknya PT. Pupuk Sriwidjaja Palembang, PPD Jateng menjadikan variabel lingkungan kerja non fisik yaitu yang berupa hubungan kerja karyawan dengan sesama rekan kerja dan hubungan kerja antara atasan dengan bawahan sebagai prioritas dalam pertimbangan membuat kebijakan perusahaan yang berkaitan dengan motivasi kerja karena variabel tersebut lebih besar pengaruhnya didalam mempengaruhi motivasi kerja karyawan.

\section{DAFTAR PUSTAKA}

Al-Omari, Jordan Khaled and Haneen Okasheh. 2017. The Influence of Work Environment on Job Performance: A Case Study of Engineering Company in Jordan. International Journal of Applied Engineering Research.vol.12. pp 1554415550

Aslinda. 2017. Pengaruh Lingkungan Kerja Dan Motivasi Kerja Terhadap Kepuasan Kerja Pegawai Pada Dinas Pekerjaan Umum Kabupaten Konawe:Universitas Halu Oleo

Ferdinand, Augusty. 2006. Metode Penelitian Manajemen, pedoman penelitian untuk penulisan skripsi, tesis, dan disertasi ilmu manajemen.Semarang:Penerbit Undip

Ferdinand, Augusty. 2014. Metode Penelitian Manajemen, pedoman penelitian untuk penulisan skripsi, tesis, dan disertasi ilmu manajemen.Semarang:Penerbit Undip

Ghozali, Imam. 2011. Aplikasi Analisis Multivariate Dengan Program IBM SPSS 19. Semarang: Badan Penerbit Universitas Diponegoro

Ghozali, Imam. 2016. Aplikasi Analisis Multivariate Dengan Program IBM SPSS 20. Semarang: Badan Penerbit Universitas Diponegoro

Lumbantoruan, Agustina. 2014. Pengaruh Lingkungan Kerja Fisik Dan Lingkungan Kerja Non Fisik di PT. Indonusa Telemedia Regional Office Jawa Barat: Universitas Telkom

Manullang. M. dan Marihot Manullang.(2015).Manajemen

Personalia. Yogyakarta: Gajah Mada University

Noor, Asmirin. 2014. Pengaruh Lingkungan Kerja Terhadap Motivasi Kerja Dan Kinerja Pegawai Di Satuan Kerja Unit Pelaksana Penimbangan (Jembatan Timbang) Dinas Perhubungan Dan Llaj Jawa Timur. Surabaya: STIE Mahardhika Riyanto, Setyo, Adi Sutrisno , and Hapzi Ali.(2017 ). The Impact of Working Motivation and Working Environment. on Employees Performance in Indonesia Stock Exchange .International Review of Managementand Marketing (IRMM).Vol.7,pp.342

Simamora, Hendra Winarta, Djamhur Hamid, Arik Prasetya. Pengaruh Lingkungan Kerja Fisik Dan Non Fisik Terhadap Motivasi Kerja Karyawan (Studi Pada Karyawan Hotel Atria \& Konferensi Malang). Malang: Universitas Brawijaya Sugiyono.2014. Metode Penelitian Bisnis. Bandung : Alfabeta

Sutrisno edy.2010.Manajemen Sumber Daya Manusia. Jakarta: kencana 
Ingsiyah, dkk/AdBis 20 (1): 83 - 92 